OPEN ACCESS

UWS Academic Portal

\title{
Physical training in team handball
}

lacono, Antonio Dello; Karcher, Claude; Michalsik, Lars Bojsen

Published in:

Handball Sports Medicine

DOI:

10.1007/978-3-662-55892-8_36

E-pub ahead of print: 11/05/2018

Document Version

Peer reviewed version

Link to publication on the UWS Academic Portal

Citation for published version (APA):

lacono, A. D., Karcher, C., \& Michalsik, L. B. (2018). Physical training in team handball. In L. Laver, P.

Landreau, R. Seil, \& N. Popovic (Eds.), Handball Sports Medicine (pp. 521-535). Springer Berlin Heidelberg.

https://doi.org/10.1007/978-3-662-55892-8_36

\section{General rights}

Copyright and moral rights for the publications made accessible in the UWS Academic Portal are retained by the authors and/or other copyright owners and it is a condition of accessing publications that users recognise and abide by the legal requirements associated with these rights.

Take down policy

If you believe that this document breaches copyright please contact pure@uws.ac.uk providing details, and we will remove access to the work immediately and investigate your claim. 


\title{
PHYSICAL TRAINING IN TEAM HANDBALL
}

\section{Antonio Dello Iacono ${ }^{1,2}$, Claude Karcher ${ }^{3}$, Lars Bojsen Michalsik ${ }^{4}$}

\author{
${ }^{1}$ The Academic College at Wingate, Wingate Institute, Netanya, Israel \\ ${ }^{2}$ Maccabi Tel Aviv FC, Tel Aviv, Israel \\ ${ }^{3}$ Laboratory of Exercise Physiology and Rehabilitation, Faculty of Sport Sciences, University of \\ Picardie, Amiens, France \\ ${ }^{4}$ Department of Sport Science and Clinical Biomechanics, Muscle Physiology and Biomechanics \\ Research Unit, University of Southern Denmark, Denmark
}

\section{INTRODUCTION}

The physical preparation of elite team handball players has become an indispensable part of contemporary professional team handball due to the high fitness level required to cope with the ever-increasing demands of match-play. The investigation of the key performance outcomes in team handball practice (see chapter XX) provides sport scientists, coaches and physical trainers with a framework for optimal planning of training. With this in mind, the aim of this chapter is to provide a general overview of the physical training principles and methodologies commonly implemented in team handball, inclusive of aerobic, anaerobic and strength training prescription.

\section{AEROBIC TRAINING}

Aerobic training sessions challenge the cardiorespiratory and metabolic systems by promoting the combustion of carbohydrates and fats in the presence of oxygen. From a physiological perspective, the most effective stimulus is induced by stressing the maximal aerobic uptake $\left(\mathrm{VO}_{2 \max }\right)$ or by working at a high percentage of $\mathrm{VO}_{2 \max }$ (Buchheit \& Laursen, 2013). This is necessary to enhance oxygen transportation and availability during oxidative metabolism processes. In practical terms, athletes should spend a certain amount of time $\left(\mathrm{T}-\mathrm{VO}_{2} \max \right)$ in their target training zone which is generally between 85 and $100 \%$ of $\mathrm{VO}_{2 \max }$. As a consequence, physical trainers in team handball should prescribe training methodologies that require players to sustain continuous type activities for long periods of time above the minimal threshold specified in their target training zone. 
A well-developed aerobic system allows team handball players to tolerate the high intensities and physiological load of the daily training, in addition to enhancing recovery between training sessions and competitions. This is especially important during long tournaments where numerous matches are played in a short period of time (Michalsik et al., 2015c). To date, most studies aiming to improve aerobic capabilities in team sports players have investigated the effect of either cardiorespiratory and metabolism-oriented (i.e., high intensity running training) (Buchheit et al., 2008), "mixed" (i.e., repeated shuttle sprints, RSS) or game-based (i.e., smallsided games, SSG) (Buchheit et al., 2009; Dello Iacono et al., 2015) training programs. Interval training (IT) is one of the most common methods used in team handball since, when adequately designed, can induce specific metabolic solicitations and matches the team handball physiological profile. Furthermore, training sessions can be performed on-court to heighten specificity and adjusted according to positional demands and the players`individual capabilities.

The effectiveness of this training methodology is optimized since intensity can be individualized and controlled using a reference for the involved workload. This is can be completed either through laboratory (Wagner et al., 2017) or field-based assessments such as the 30-15 (30-15 IFT) (Buchheit et al., 2008b) or Yo-Yo intermittent fitness tests (Hermassiet al., 2010; Michalsik et al., 2015c). The intensity of the prescribed interval bouts can then be individualized and will range between $85 \%$ and $105 \%$ of their Maximal Aerobic Speed (MAS) determined through laboratory assessment, Yo-Yo tests (Hermassi et al., 2010; Michalsik et al., 2015c) or 30-15 IFT final speeds ( $\left.\mathrm{V}_{\mathrm{IFT}}\right)$. The prescription of IT exercise can be manipulated to induce different physiological and performance adaptations and, in turn, help in matching the short- and long-term periodization plans (Buchheit \& Laursen, 2013). Following the list of the methodological variables for the IT planning:

$\begin{array}{ll}\text { - } & \text { Exercise modality } \\ \text { - } & \text { Work interval intensity } \\ \text { - } & \text { Work duration } \\ \text { - } & \text { Number of repetitions } \\ \text { - } & \text { Dumber of series } \\ \text { - } & \text { Recovery modality (active vs. passive) and intensity }\end{array}$

In terms of exercise modality, aerobic IT formats can be classified as either long or moderate intervals which may be performed as repetitive runs. In general, the longer the $\mathrm{T}-\mathrm{VO}_{2} \max$, the 
higher solicitation of the $\mathrm{VO}_{2 \max }$ and as a consequence, greater aerobic effects are induced. In practice, the total work duration of any aerobic training format should be related to the goals of the sessions in terms of $\mathrm{T}-\mathrm{VO}_{2} \max$ and $\mathrm{T}-\mathrm{VO}_{2 \max } /$ exercise time ratio, also defined as the effective time spent at $\mathrm{T}-\mathrm{VO}_{2}$ max in relation to the total training session duration, without neglecting the time necessarily needed to reach the $\mathrm{VO}_{2 \max }$. The manipulation of different IT formats can induce the physiological responses required for improving aerobic capacities whilst also matching the specific demands of the team handball by recreating on-court game-like situations (Dello Iacono et al., 2015; Michalsik, 2015). In team sports, $\mathrm{T}-\mathrm{VO}_{2 \max }$ of 5-7 minutes is likely sufficient to induce important cardiopulmonary adaptations and for maintenance during tapering periods. To maximise $\mathrm{T}-\mathrm{VO}_{2 \max }$ during formal aerobic training, running speeds ranging between $90 \%$ and $105 \%$ of the minimal velocity associated with the $\mathrm{VO}_{2 \max }\left(\mathrm{vVO}_{2 \max }\right)$ have been suggested (Billat, 2001; Buchheit and Laursen 2013). These intensities elicit high contributions from aerobic metabolism (above $95 \%$ of the total energy) with marginal solicitation of the anaerobic pathways and peripheral effects due to the involvement of the neuromuscular system.

Long IT formats are typically implemented in training sessions lasting between 10-20 min and can be implemented using a variety of methodologies (Table 1). Passive recovery is commonly recommended between sets, with rest periods lasting 2-3 min in duration. However, if an active recovery is chosen, the rest periods should last at least 3-4 min depending on the duration of the running intervals, and should be performed at a submaximal intensity $\left(\leq 40 \% \mathrm{VO}_{2 \max }\right)$ to allow the maintenance of high intensity outputs during the subsequent interval work periods. Evidence suggests that elite athletes tend to be more efficient in accumulating greater $\mathrm{T}-\mathrm{VO}_{2 \max }$ compared to less trained athletes (Buchheit \& Laursen, 2013). In addition, the choice of the work interval duration seems to be critical especially at the beginning of the training session when a certain amount of time is necessary to accelerate the $\mathrm{VO}_{2}$ kinetics until reaching the $\mathrm{VO}_{2 \max }$ (Gerbino et al., 1996). Thus, since the $\mathrm{VO}_{2 \max }$ is not reached on the first work period in short IT formats, an adequate warmup is strictly recommended.

For short IT formats the main focus should be applied to adjustments in work and rest periods to maximise the $\mathrm{T}-\mathrm{VO}_{2}$ max. Team handball physical trainers should design short IT sessions with the goal of being time-efficient and to optimise the $\mathrm{T}-\mathrm{VO}_{2}$ max $/$ exercise time ratio. Keeping in mind the importance of $\mathrm{VO}_{2}$ kinetics for improving the $\mathrm{T}-\mathrm{VO}_{2}$ max , it is suggested to perform short IT training sessions organised in 2-3 series of 8-12 min, include short bouts (10-20 repetitions of 10-30s) of formal running at intensities between $90 \%$ and $105 \%$ of $\mathrm{vVO}_{2 \max }$ interspersed by rest periods of fixed or similar durations (Billat, 2001). The characteristics and intensity of the rest interval play a major role in determining the contribution of aerobic pathways 
during IT due to its effect on the exercise $\mathrm{VO}_{2}$. Also the total exercise duration should be considered as this will indirectly alter the $\mathrm{T}-\mathrm{VO}_{2 \max }$. In general, compared to short IT formats with passive recovery, exercise modalities involving active recovery are 30 to $60 \%$ shorter in terms of total work duration. In these scenarios, the manipulation of the active recovery intensity ensures a similar absolute $\mathrm{T}-\mathrm{VO}_{2} \max$ regardless of the lower total work time. The implementation of active recovery modalities has been shown to compensate for the relatively shorter duration of total work time, inducing substantially greater $\mathrm{T}-\mathrm{VO}_{2} \max$ and $\mathrm{T}-\mathrm{VO}_{2 \max } /$ exercise time ratio outcomes when compared to exercise modalities of similar work intensities but including passive recovery (Ahmaidi et al., 1996). More precisely, the intensity of the active recovery represents a factor worthy of consideration when designing and planning IT sessions. In fact, the recovery intensity likely dictates the effectiveness of the training sessions ability to increase both the $\mathrm{T}-\mathrm{VO}_{2} \max$ and $\mathrm{T}-\mathrm{VO}_{2 \mathrm{max}} /$ exercise time ratio. However, the effects can be highly variable, with improvements ranging from small to very large in the above mentioned metabolic indexes. The current literature suggests that for team-sport athletes performing very short IT formats including 10-30s run bouts, rest periods $\leq 15-20$ s at an intensity around $40-50 \%$ of $\mathrm{VO}_{2 \max }$ (Buchheit \& Laursen, 2013)..

Table 1. The principles for formal and on-court aerobic training aerobic training. The exercise intensity is expressed in percentage of the maximal aerobic speed (MAS). The recovery modality is expressed as active (A) or passive (P); whether active the designed intensity is expressed as relative to MAS as well; ${ }^{*}$ between repetition; ${ }^{\#}$ between series

Duration

Training methodology

Repetitions

Single repetition

Exercise intensity

Recovery

(Nr.)

(min)

$\%$ MAS

(min)

Long Interval Training
a) Passive inter-set recovery
$5-10$
$2-3$
$90 \%$
$\mathrm{P} ; 1-2$ at $0 \%$
b) Active inter-set recovery
$5-6$
3-5
$>90 \%$
A; $2-3$ at $40-50 \%$
c) Active inter-set recovery
$3-4 \times 2$
2
$100 \%$
*A; 2 at $50 \%$

Short Interval Training

(s)

${ }^{\#} \mathrm{P} ; 3-4$ at $0 \%$

a) Passive inter-rep recovery

10-12

30

$90 \%$

(s)

b) Passive inter-set and inter-

$2 \times 10-20$

20

$95 \%$

rep recovery

P; 30 at $0 \%$

${ }^{*} \mathrm{P} ; 20$ at $0 \%$

${ }^{\#} \mathrm{P} ; 120$ at $0 \%$

${ }^{*} \mathrm{P} ; 15$ at $0 \%$ 


\begin{tabular}{|c|c|c|c|c|}
\hline c) Passive inter-set and inter- & $2 \times 16-20$ & & $100 \%$ & ${ }^{\#} \mathrm{P} ; 120$ at $0 \%$ \\
\hline $\begin{array}{l}\text { d) Active inter-rep and } \\
\text { passive inter-set recovery }\end{array}$ & $2 \times 20$ & 10 & $105 \%$ & $\begin{array}{l}{ }^{*} \mathrm{~A} ; 15-20 \text { at } 40-50 \% \\
{ }^{\#} \mathrm{P} ; 120-180 \text { at } 0 \%\end{array}$ \\
\hline
\end{tabular}

\title{
On-court aerobic training
}

The Short Interval Training modalities b, c, d could be designed as on-court aerobic training formats by converting the final speeds of both laboratory and field-based assessment tests into running distances according to the individual players own`s capacity. Coaches and physical trainers should accurately consider and adjust the running paths, amount of high intensity presence of acceleration and decelerations actions, number of changes of direction (COD) and their directional angles. As general guideline, the greater the amount of accelerations, decelerations, CODs and the more acute the angle of the COD, the higher the neuromuscular responses and the contribution of the peripheral system.

\section{Key points of aerobic training}

- Necessary preliminary aerobic capacity assessment

- $\quad$ Training target zones between 85 and $100 \%$ of $\mathrm{VO}_{2 \max }$

- Individualised intensity

- $\quad$ Training format (Long and/or short IT with active or passive recovery) selection according to the specific demands ( $\mathrm{T}-\mathrm{VO}_{2 \max }$ and $\mathrm{T}-\mathrm{VO}_{2 \max } /$ exercise time ratio).

- $\quad$ Continuous running (e.g. $15 \mathrm{~min}$ at $90 \%$ of maximal Heart rate)

- $\quad$ Low-intensity running as recovery training

\begin{abstract}
ANAEROBIC TRAINING
Previously, working demands analyses of elite team handball have been performed (Sibila et al., 2004; Pori \& Sibila, 2006; Luig et al., 2008; Michalsik et al., 2013, 2014, 2015 a,b,c - see chapter 3). These study data indicate a high need for superior acceleration and deceleration capacity, high rates of force development (RFD), and a high ability to perform explosive jumps, fast and hard shots, rapid side-cutting manoeuvres, powerful changes of direction and agility movements, and strength demanding physical confrontations. e.g. tackles and screenings. In addition, the intermittent high-intensity running capacity also seems crucial for playing performance (Michalsik et al., 2013, 2014).
\end{abstract}


Based on scientific data (Sibila et al., 2004; Luig et al., 2008; Michalsik et al., 2013, 2014), high-intensity running does not represent much of total effective playing time. However, the ability to continuously change pace and accelerate throughout the entire match is likely of high? importance for top-level playing performance. Thus, an intensified focus on anaerobic training aspects and resistance training seems highly relevant especially for male elite team handball players (Michalsik \& Aagaard, 2015). It is clear that anaerobic exercises should be a key focus with regards to the training of elite team handball players for improving their ability to repeatedly perform anaerobic exercise and to rapidly recover after periods of high-intensity exercise. Consequently, the players will be more capable of performing the above playing actions at sustained high levels throughout the entire match. Even though almost all kind of strength training due to the high intensity and short exercise duration is anaerobic of nature, it is described in a separate section.

\section{Anaerobic training}

Anaerobic training can be divided into two main training areas (Michalsik, 2015 - see table 1):

- Speed training

- Speed endurance training

The latter can be further divided into:

- Production training

- Maintenance training

The benefits of anaerobic training for elite team handball players are an improved performance of intense match activities such as accelerations, change of directions, jumps, shots and tackles, and furthermore an elevated ability to perform very high-intensity exercise more frequently and for longer time periods. The three training areas are overlapping (see Table 2). They are all performed with a much higher intensity than in aerobic training, i.e. with an intensity corresponding to over $\mathrm{VO}_{2}$-max (Bangsbo \& Michalsik, 2018). Consequently, all anaerobic training must be performed according to the interval principle. Large quantities of anaerobic training should only be performed at an elite level, since it is a physical and mentally demanding type of training. Since the effects of anaerobic training mostly occur in the muscles used during training, anaerobic training in elite team handball should be performed on-court with a ball, i.e. conducted in a manner similar to actual team handball match-play. 
Table 2. The principles for formal anaerobic training. The exercise intensity is expressed in percentage of the individual maximal exercise intensity. When the training is conducted with the ball, the ratio between the duration of exercise and rest/active recovery can often be reduced compared to the values presented, since the players are not constantly working at high intensities due to natural variations in the game.

\begin{tabular}{|c|c|c|c|c|}
\hline \multirow{2}{*}{ Training area } & \multicolumn{2}{|c|}{ Duration } & \multirow{2}{*}{ Exercise intensity } & \multirow{2}{*}{ No. of repetitions } \\
\hline & Exercise (s) & Rest & & \\
\hline Speed training & $2-10$ & $\begin{array}{l}>10 \text { times exercise } \\
\text { duration }\end{array}$ & $100 \%$ & $2-15$ \\
\hline Production training & $10-40$ & $\begin{array}{l}>10 \text { times exercise } \\
\text { duration }\end{array}$ & $60-100 \%$ & $2-15$ \\
\hline Maintenance training & $10-120$ & $\begin{array}{l}\text { 3-5 times exercise } \\
\text { duration }\end{array}$ & $30-100 \%$ & $2-15$ \\
\hline
\end{tabular}

In speed training, the players must exercise with maximal intensity for short periods of time (less than 10 seconds). Thus, it is no problem to find the right training intensity. It may be harder during on-court speed endurance training, but with experience it will be easier. If the training is performed as formal running, it is relatively easy to control the intensity, as the correct load can be found as a certain time relative to the time at the distance in question, when maximal exercise is performed a single time.

Since the intensity of anaerobic training is very high, it requires great motivation from the players to complete. Measurement of heart rate can be utilised during speed endurance training sessions as an indicator of whether the training is being conducted with sufficient intensity. For longer periods of exercise ( $>1$ minute), the heart rate should be close to maximal values at the end of the exercise periods. However, for short periods of work ( $<1$ minute), the heart rate will not be able reach maximal values and therefore cannot be used to assess the training intensity.

\section{Speed training}

The aims of speed training are to increase the ability to perceive match situations, to take immediate actions when needed, and finally to increase the ability to rapidly produce force during high-intensity exercise. During speed training, the players should perform maximally each time for less than 10 seconds.

There are three key factors in the concept of speed: 
- Reaction speed, which is the ability to react quickly and efficiently at the starting time.

- Acceleration capacity, which is the ability to quickly increase the speed from zero to maximum.

- Maximum running speed, which is the players highest speed.

Match analyses of elite team handball have shown that speed training in team handball primarily should target reaction speed and acceleration capacity (i.e. RFD) rather than focus on maximum running speed (Michalsik et al., 2013, 2014). The mean duration of a sprint action was calculated to be $1.0 \mathrm{~s}$ corresponding to a running distance covered of approximately $7 \mathrm{~m}$ (Michalsik et al., 2013). Thus, in team handball it is important to react quickly and perform powerful changes in direction, while moving quickly over short distances $(<15 \mathrm{~m})$.

When team handball players are required to react quickly at the start of a fast break or during a quick breakthrough, rapid force production is required in limited time-frames to effectively perform game specific activities. It usually takes about half a second to achieve maximum force in the skeletal muscle (Aagaard et al., 2002; Aagaard, 2003). The ability to generate high RFD is often more important in team handball than high maximum strength. This ability is trained by heavy, explosive strength training (also called RFD-training), and strength training is therefore an important supplement to the actual speed training in team handball. The result of such strength training will be e.g. an increased acceleration ability, if the effect of strength training is "transferred" to the right movement pattern during match-play via functional speed training (Michalsik, 2015).

Most of the physiological effects of speed training are derived from adaptations in the central nervous system (spinal cord and brain), and its interaction with the recruited musculature. Therefore, it is pivotal that this interaction is trained under situations that are most similar to the situation during match-play. This means under conditions where the training drills are performed with maximum effort with fresh muscles, where the coordination pattern is trained with the muscle fibers activated in the right order at the right speed (Bangsbo \& Michalsik, 2018). Furthermore, training regimens for the development of speed should also include a lot of coordination and strength training exercises. The fundamentals of sprint mechanics must be trained, even in team handball. When moving as fast as possible, the players must be able to perform the correct technique automatically, as there is no time to think about this during the actual performance during match-play. However, another approach could be to physical overload especially players with poor technical skills, since they will not be able to perform on-court speed exercise drills with maximal intensity. This will require formal speed training in non-match situations. These 
training effects should then be incorporated into match-play be performing on-court speed training with the ball. This interesting concept needs to be examined in future studies.

Speed training should be performed in the beginning of the training session when the players are not tired and after a proper warm-up. Speed training should mainly be performed as on-court functional speed training performed with the ball in match-like situations instead of formal speed training, since part of the desired training effect is to improve the player's ability to anticipate, evaluate and decide in different situations in team handball, e.g. the start signal could be the completion of a shot or the bounce of a ball. In team handball, speed is not just a matter of physical capacity, it also involves quick decisions that must then be transferred into fast actions. When formal sprinting without a ball, e.g. running after signal from the trainer, it is mainly the acceleration capacity and the ability to fast anaerobic energy turnover that is trained. This form of training can only be used to a small extent to train the reaction speed in team handball, as the signals (e.g. whistle) the players must react on do not resemble those they are exposed to during match-play (Michalsik, 2015). However, as mentioned earlier this training may be relevant in special situations when trying to physical overload players with poor technical skills.

Additionally, during match-play sprinting there are usually directional changes depending on where the opponents are or where the ball is when passed between players. Often the accelerations/deaccelerations occur with whole or partial body contact with opponent players. In team handball, the player's coordination pattern when sprinting is therefore a lot different than, for example, when sprinting in track and field. As the training specificity is high, it means that certain muscle fibers used during sprinting in team handball are not trained and others are trained in the wrong movement pattern (Bangsbo \& Michalsik, 2018).

The periods between the exercise bouts should be long enough for the muscles to recover to near resting conditions to enable the players to perform maximally in subsequent exercise bouts. Previous studies have shown that the performance of repeated sprints can be maintained, if the duration of the pauses is more than 10 times the length of exercise period (Balsom et al., 1992). The longer the exercise time (sprint distance), the higher the relationship between the duration of exercise period and the pause must be. Speed training should therefore be carried out with at least a pause duration of 10 times the length of exercise period to be effective. High concentration and great will are essential for achieving an optimal training effect.

\section{Key points of speed training}

- $\quad$ Thorough warm-up 
- Maximal intensity

- High concentration and motivation

- $\quad$ Few repetitions

- $\quad$ Long pauses, exercise-to-rest/active recovery ratio $>1: 10$

- $\quad$ Should be performed in the start of the training session

- $\quad$ Should mostly be performed with the ball

\section{Speed endurance training}

The purpose of production training is to increase the ability to rapidly produce power and energy via the anaerobic energy-producing systems, and thus improve the ability to perform maximally for a relatively brief period. whereas the aim of maintenance training is to increase the capacity to continuously produce power and energy through the same energy systems, and hereby improve the ability to sustain exercise at a high intensity. Both training regimens also aim to increase the ability to recover after very high-intensity exercise.

Findings of high post-match blood lactate concentrations of 2-10 $\mathrm{mM}$ in elite team handball players in connection with tournament matches (Michalsik et al., 2015c) indicate that the glycolytic energy system is highly stimulated during certain periods of the game. Moreover, match analyses of elite team handball have revealed that the amount of high-intensity running may be very high in brief time intervals, and indications of temporary fatigue and impaired physical performance have been observed reflected by a reduced amount of high-intensity running and technical playing actions in the second half (Michalsik et al., 2013, 2014, 2015a). Additionally, the ability to continuously exercise at very high intensities throughout the entire match seems to be crucial for top-level playing performance in team handball. Consequently, speed endurance training including training of the repeated sprint ability must be an integrated part of the physical training for elite team handball players.

\section{Production training}

If team handball players during match-play e.g. are performing a fast break immediately followed by a quick retreat and some intensive defensive actions in a relative brief period of time, they must be able to produce a high amount of energy very fast. Production training increases the ability to break down ATP and PCr quickly, as well as increasing the maximum rate of the glycolysis. A high exercise intensity is essential for increasing the rate of these energy systems, and the intensity should not be less than $60 \%$ of the maximum exercise intensity. The duration of the individual exercise bout should not be too short, because it takes about 10 seconds before the glycolysis runs 
at maximum velocity (Bangsbo \& Michalsik, 2018). The exercise bouts less than 10 seconds are too short for optimal training effects on the anaerobic metabolism. Conversely, the exercise periods should not be longer than 40 seconds, as it is approximately the limit for how long such intensity can be maintained when the exercise is repeated several times one after the other during a single training session. Consequently, in production training the duration of the exercise bouts should be relatively short (10-40 seconds), and the rest periods in between should be comparatively long (2-7 minutes) to maintain a very high intensity throughout the training.

Production training should take place with long rest periods (Bogdanis et al., 1995). In experiments where 6 seconds of maximum intensity on a bike were repeated 10 times with 30 second pause in between each sprint bout, the rate of the glycolysis decreased markedly as the bouts were repeated. The exercise-to-pause ratio was 1:5 and not sufficiently high to maintain a high glycolysis rate. Thus, the training effect on the maximum glycolysis rate was not optimal. Production training should therefore at maximum intensity be carried out with at least a pause duration of 10 times the length of the exercise period to be as effective as possible (see Table 1).

Production training is normally placed at the end of the training session, as the training is so physical and psychologically demanding that the players may be affected for a while afterwards. Sometimes it may be an advantage to place production training early in the training session. Especially if the players have been training for a long time - e.g. more than 1 hour of team handball training - before the actual production training, you may risk that many muscle fibers are completely or partially emptied of glycogen when the production training starts. This makes it difficult to recruit sufficient muscle fibers and maintain an exercise intensity within the primary area of production training (Bangsbo \& Michalsik, 2018). However, it is not recommended to train technical skills after production training.

\section{Key points of production training:}

- $\quad$ Short exercise periods at $60-100 \%$ of maximum intensity

- $\quad$ Long pauses, exercise-to-rest/active recovery ratio $>1: 10$

- Normally placed in the end of the training session

- $\quad$ Should be performed with the ball

- $\quad$ Should be followed by recovery activities

- $\quad$ Performed primarily at the elite level

\section{Maintenance training}

When team handball players during match-play are performing a very intensive organized offensive or defensive play, or are performed numerous fast breaks and quick retreats right after 
each other, they must be able to maintain a high exercise intensity for a prolong time period even though they are beginning to become fatigued. When training to increase the ability to tolerate, neutralize and eliminate fatigue substances in the working muscles, the exercise intensity must also be high. In maintenance training, the exercise periods should be 10-120 seconds, whereas the duration of the rest periods should only be a little longer than the exercise periods., if the training is performed with a ball, so that the players become progressively fatigued (see Table 1). Maintenance training should be performed at the end of the training session, because the training is so demanding that players will be physically affected for a long time afterwards (Bangsbo \& Michalsik, 2018).

As the training gradually becomes more strenuous to the player, it is important to continue with the highest possible intensity. It is a matter of achieving a high accumulation of fatigue substances, so that the muscles in this way can increase the ability to tolerate, neutralize and eliminate of the accumulated fatigue substances. The pauses between the exercise bouts must be relatively short (3-5 times the length of exercise periods), as the players at next repetition already from the start should have an increased concentration of fatigue substances in the muscles (Michalsik, 2015). However, the pauses must not be too short, as it is thus not possible to maintain the exercise intensity within the primary area of tolerance training, and the training effect in the last exercise periods will be too low. The exercise periods should not be longer than 2 minutes, as it is approximately the limit for how long an intensity corresponding to just over $\mathrm{VO}_{2}-\mathrm{max}(\sim 30 \%$ of maximum intensity) can be maintained when the exercise is repeated several times one after the other during a single training session (Bangsbo \& Michalsik, 2018). If the players are very well-trained (faster recovery), the pauses can be shorter. Often, team handball players do not have sufficient patience to complete the initial exercise bouts with proper low intensity. Furthermore, it is also important for the unexperienced player not to make the pauses too short.

\section{Key points of maintenance training}

- $\quad$ Exercise intensity at 30-100\% of maximum intensity

- Relatively short pauses/active recovery, 3-5 times exercise duration

- Must be performed at the end of the training session

- $\quad$ Should be performed with the ball

- $\quad$ Should be followed by recovery activities

- $\quad$ Performed primarily at the elite level 
In exercise drills with the ball during all kinds of anaerobic training, the intensity of each player depends on how many players are involved in the drill. With many players, situations will often occur, e.g. when the ball is far away from the player or when the ball is out of play, where the player's intensity will decrease, and therefore the duration of the pauses can be reduced compared to the length of the exercise. With few players in an exercise drill, it is easier to control the intensity of the individual player, and there will be fewer periods where the intensity is not high enough. It is important that there always is access to many balls, so that there is no break in the exercises.

\section{STRENGTH TRAINING}

In team handball, as for many other team sports, the design and methodological application of strength training modalities should address two main objectives: injury prevention and performance enhancement. In light of the strenuous nature of the team handball discipline, involving high intensity short-duration activities such as sprinting, jumping, turning, pushing, blocking, throwing and ability to perform effective defensive interventions (Michalsik \& Aagaard, 2015, Michalsik et al., 2013), a systematic and progressive strength training plan could lead to the improvement of specific capabilities representing the physical prerequisite for successful participation at elite level (Cormie, McGuigan, \& Newton, 2011).

In order to design an efficient strength training program in team handball, it is fundamental for physical trainers to have a wide understanding of the game performance model and the respective demands (see chapter $\mathrm{X}$ ) in terms of specificity. Specificity is a crucial aspect to consider when trying to transfer the physical improvements achieved through physical training programs into playing performance (Issurin, 2013). It is widely documented that any specific physical training program should be carried out matching a comprehensive analysis of the playing demands (see chapter XX). The key training principles for strength training in team handball, and the biomechanical aspects regarding the nature of their execution and the training contents and modalities commonly adopted are described in this section.

\section{Strength training methodology for developing athletes}

A team handball player`s career can easily span around 20 years and, as a consequence, strength training programs should be designed and developed with a long-term athletic development focus. Although certain phases of a team handball player`s development or specific positional demands due his role may require attention, the strength training journey may be 
considered as a long-term model with well-defined objectives, contents and methodologies for each stage. The best approach to design individualized strength training programs for team handball players consist in firstly collect information about their injury history, then assess strength and weaknesses, and finally create a progressive plan which takes into consideration the needs to develop strength capabilities which can both positively affect performance and limit future injury occurrence.

In literature, little is known about the most appropriate approaches for a periodized strength training programs. In our experience, strength training should be realized considering consecutive stages leading to a progressive and resilient development of future athletes. Indeed, an accurate planning, made by the coaching staff, is required for appropriately managing the overall loading experienced by the athletes in order to avoid unfunctional overreaching and/or overtraining effects. From a methodological perspective, strength training should be performed weekly with one to three sessions per week according to the targeted objectives, the training schedule and the congested matches fixture. As common practice, two sessions per week can be useful to improve strength and power in well-trained individuals (Dello Iacono et al., 2017; Hermassi et al., 2010; Marques et al., 2006), with three sessions per week being more appropriate in pre-season or intensive preparation periods. Single sessions per week are unlikely to produce significant improvements in strength and power, but can be useful to maintain strength and power levels in well-trained players (Cormie et al., 2001; Markovic et al., 2010).

The training contents selection and the associated load progression should include some elements of heavy strength training focusing on cumulative muscular adaptations with emphasis on hypertrophy and maximal strength development. The following training stages should address explosive force, muscle power and rate of force development (RFD) with the aim to induce transfer effects on the specific handball-related skills performances. Accordingly, the training methodologies can systematically vary over the course of the athletes` development. Evidences suggest larger volumes of progressive heavier loads (>80\% of 1RM) at the beginning of the career, in case of young in-development athletes, or during in-season phases in professional teams. Then, the emphasis is shifted gradually to larger volumes of lighter loads (loads aiming to maximise impulse-dependent mechanical capabilities such as RFD and power) and more explosive movements with an overall reduction of training volume towards later stages of development or in very congested in-season periods. As general rule, the ultimate objective of an ideal approach should be to effectively improve the force/velocity and power/velocity relationships (Morin and Samozino, 2016) thus optimizing neuromuscular adaptations. Table 3 details the main stages to 
consider for an appropriate strength training development with both the training principles and methodological guidelines targeting their associated objectives.

Table 3. The principles for strength training. The exercise intensity is expressed in percentage of the one-repetition maximum (1RM).

\begin{tabular}{|c|c|c|c|}
\hline Stage & Objectives & Contents & Methodology \\
\hline $\begin{array}{l}\text { 1. Introduction to } \\
\text { strength training }\end{array}$ & $\begin{array}{l}\text { - Learn to develop force } \\
\text { - Control and stabilization of the } \\
\text { limbs during basic movement } \\
\text { - Focus on technique and control }\end{array}$ & $\begin{array}{l}\text { Multi-joint body-weight exercises } \\
\text { with low resistance such as through } \\
\text { using elastic bands, medicine balls } \\
\text { or sand bags }\end{array}$ & $\begin{array}{l}2 \text { x } 15 \text { reps } \\
\text { Rec: } 1^{\prime} \\
3 \text { x } 8-10 \text { reps } \\
\text { Rec: } 1^{\prime}\end{array}$ \\
\hline $\begin{array}{l}\text { 2. Introduction to } \\
\text { general strength } \\
\text { and hypertrophy }\end{array}$ & $\begin{array}{l}\text { - Learn to develop force with } \\
\text { greater overloads } \\
\text { - General strengthening of the } \\
\text { musculoskeletal system } \\
\text { - Induce appropriate levels of } \\
\text { hypertrophy }\end{array}$ & $\begin{array}{l}\text { Multi-joints barbell or resisted } \\
\text { exercises such as squat, lunges, } \\
\text { deadlift, hip thrust, bench press, } \\
\text { overhead press exercises } \\
\text { Single or multi-joint exercises with } \\
\text { free weights or dumbbell including } \\
\text { different pulling and pushing } \\
\text { moves variations }\end{array}$ & $\begin{array}{c}\text { 4-6 x 4-6 reps } \\
\text { loaded 80-85\% } 1 \mathrm{RM} \\
\text { Rec: > 2' } \\
\text { 3-4 x 10-12 reps } \\
\text { loaded } 60-80 \% 1 \mathrm{RM} \\
\text { Rec: } 1^{\prime}-1 ' 30 "\end{array}$ \\
\hline $\begin{array}{l}\text { 3. Maximal } \\
\text { strength training }\end{array}$ & $\begin{array}{l}\text { - Maximize and maintain } \\
\text { strength levels by the regular use } \\
\text { of key strength exercises }\end{array}$ & $\begin{array}{l}\text { Multi-joints barbell or resisted } \\
\text { exercises such as squat, lunges, } \\
\text { deadlift, hip thrust, bench press, } \\
\text { overhead press exercises } \\
\text { Large use of weightlifting } \\
\text { techniques where appropriate }\end{array}$ & $\begin{array}{c}\text { 4-6 x 2-5 reps } \\
\text { loaded } 85-95 \% 1 \text { RM } \\
\text { Rec: }>3 \text { ' } \\
\text { Periodization models } \\
\text { according to the } \\
\text { competitive schedule } \\
\text { and development level }\end{array}$ \\
\hline 4. Power training & $\begin{array}{l}\text { - Learn to develop force rapidly } \\
\text { emphasizing rapid } \begin{array}{l}\text { speed of } \\
\text { movement } \\
\text { resistance }\end{array}\end{array}$ & $\begin{array}{l}\text { Body-weight hops, jumps drop } \\
\text { jumps, barbell jump squats } \\
\text { Medicine balls throws, bench } \\
\text { throws, push presses }\end{array}$ & $\begin{array}{c}\text { 3-5 x 6-10 reps } \\
\text { Rec: 1'-2' } \\
\text { 3-5 x 4-6 reps } \\
\text { loaded 30-50\% } 1 \mathrm{RM} \\
\text { Rec: > 2' }\end{array}$ \\
\hline $\begin{array}{l}\text { 5. Explosive } \\
\text { strength or } \\
\text { rate of force } \\
\text { development } \\
\text { (RFD) training }\end{array}$ & $\begin{array}{l}\text { - Learn to develop the maximum } \\
\text { amount of force or impulse in a } \\
\text { minimum amount of time }\end{array}$ & $\begin{array}{l}\text { Multi-joints barbell or resisted } \\
\text { exercises such as squat, lunges, } \\
\text { deadlift, hip thrust, bench press, } \\
\text { overhead press exercises } \\
\text { Olympic weightlifting such as } \\
\text { cleans, power cleans, snatches, } \\
\text { jerks }\end{array}$ & $\begin{array}{c}3-5 \text { x 2-4 reps } \\
\text { loaded 30-70\% } 1 \mathrm{RM} \\
\text { Rec: }>2^{\prime} \\
3-5 \text { x 1-2 reps } \\
\text { loaded }>85 \% 1 \mathrm{RM} \\
\text { Rec: }>3^{\prime}\end{array}$ \\
\hline
\end{tabular}

\section{Training specificity: the force-vector hypothesis}

The force vector hypothesis (Morin \& Samozino, 2016) and the principle of movement specificity between functional tasks and the physical activities performed must be carefully considered when designing interventions to achieve the desired adaptation. Recently, it has been 
suggested that performance adaptations to strength training may occur through the specificity of the force vector application which provides transfer effects toward the specificity of the sporting performance demanding a similar force production and application (Dello Iacono, Martone, Milic, \& Padulo, 2017). For example, hip thrust exercises have been shown to be more effective than squat exercises for improving acceleration and sprinting tasks due to the similarity in the motor pattern, hip and knee joints involvement and force orientation production (Contreras et al., 2017, Dello Iacono et al., 2017b). Similar trends were found with regard to change of direction drills and the same conclusions were drawn following plyometric training with team handball players (Dello Iacono et al., 2017a). These findings have a great potential for team handball players since strength training programs implementing the force-vector specificity principle may be prescribed as specifically-oriented exercises, which improve force production and related functional physical performance according to the specific task, the performance model, and playing demands in team handball.

\section{Training contents and modalities}

In keeping with the specificity principle mentioned above, the strength training program must be directed at improving the force production capacity of the upper and lower limb muscles. This approach will aid in force transfer within and between the body structures and promote their long-term resilience due to the continuous involvement into repetitive and high-intensity demanding actions. Planning a periodization program for team handball players is complicated by the many diverse factors affecting performance. Beside them, it is worth to consider: players gender and their maturation stage, competitive level, length of the competitive season, phase of the season, training experience in general and for resistance training in details, playing position, special needs, weaknesses and previous injury record. In general, when considering the time course of the specific adaptations induced by strength training contents commonly used in team handball, it is useful to categorize the induced effects in acute or short-term adaptations and chronic or long-term adaptations.

\subsection{Acute or short-term adaptations}

Strength training and the different resistance exercises variants are recognized as beneficial training tools for acutely enhancing functional tasks, according to the known phenomenon called post-activation potentiation (PAP) (Sale, 2002). PAP refers to the acute enhancement of muscular function as a direct result of its contractile history (Sale, 2002). The literature suggests that the 
PAP effects may be affected by several physiological and training variables including: the type of exercising muscle fibres (Sale, 2002); the subject's fitness characteristics; the type, duration, volume and intensity (McBride et al., 2005) of the conditioning activity (CA) used for achieving the potentiation effects (Seitz \& Haff, 2016); the length of the period following the CA (Wilson et al., 2013); the type of subsequent activity (Seitz \& Haff, 2016). Recently, in team handball, Dello Iacono et al. (2016) reported a potentiation effect on $25 \mathrm{~m}$ sprints and change of direction ability after 8 minutes following a protocol including horizontal-alternate one-leg drop jumps. In light of the acute biomechanical adaptations associated with PAP protocols, the applicability of training regimens in terms of PAP exercises is recommended to coaches and team handball players as either warm-up strategies aiming to acutely improve subsequent functional performances, or as part of complex programs of sprinting training (Dello Iacono et al., 2017b).

\subsection{Chronic or long-term adaptations}

Strength training regimens are widely recognized as potential tools for enhancing sports performance, and have been extensively correlated with specific motor tasks and physical requirements of the athletic models of interest. Scientific studies generally report strength training regimens to be an effective mean for improving strength capabilities, and explosive neuromuscular impulse-dependent components such as acceleration, jumping, sprinting, change of direction (COD) ability, throwing (Hermassi et al, 2010; Markovic \& Mikulic, 2010). Table 4 reports a wide range of training methodologies commonly adopted in the daily team handball practice and the chronic adaptations induced when designed as long-term strategies.

Table 4. Current evidences for strength training in team handball

\begin{tabular}{|c|c|c|c|c|}
\hline Study & Population & Duration & Methodology & $\begin{array}{c}\text { Performance } \\
\text { Outcomes }\end{array}$ \\
\hline Barata & $\begin{array}{c}12 \text { Male amateur } \\
\text { players }\end{array}$ & $\begin{array}{c}9 \text { weeks } \\
\text { (3 sessions/week) }\end{array}$ & $\begin{array}{c}\text { Full body training (8 } \\
\text { exercises) } \\
2-3 \text { sets x } 8 \\
\text { (light overload: } 1-12 \\
\mathrm{~kg} \text { ) }\end{array}$ & $\begin{array}{c}\uparrow 3.7-6.9 \% \text { Throw } \\
\text { speed release }\end{array}$ \\
\hline $\begin{array}{c}\text { Cardoso \& González- } \\
\text { Badillo }\end{array}$ & $\begin{array}{c}16 \text { Male professional } \\
\text { players }\end{array}$ & $\begin{array}{c}12 \text { weeks } \\
(2-3 \text { sessions/week })\end{array}$ & $\begin{array}{c}\text { Complex training } \\
\text { (Bench press, Squat, } \\
\text { Squat Jumps, }\end{array}$ & $\begin{array}{l}\uparrow 3.3 \% 30-\mathrm{m} \text { sprint } \\
\uparrow 2.3 \% 15-\mathrm{m} \text { sprint } \\
\uparrow 6 \% \text { Throw speed }\end{array}$ \\
\hline
\end{tabular}


18 Male professional players

10 Female first-third national level

10 male adolescent players

Gorostiaga et al.

Gløssen

Hermassi et al
10 weeks

(2 sessions/week)

8 weeks

(3 sessions/week)

6 weeks

(2 sessions/week)
26 Male professional players
Countermovement

Jumps, Box Jumps, Sprints)

2-3 sets x 3-6 at 7095\% 1RM
3 sets $x 6$ Pulley

exercise $(85 \%$ 1RM) $\uparrow 20.8 \%$ Loaded (20-

$\mathrm{kg}) \mathrm{CMJ}$

$\uparrow 25.8 \%$ Loaded (40-

$\mathrm{kg}) \mathrm{CMJ}$

$\uparrow 13 \% \mathrm{CMJ}$

$\uparrow 27.7 \% 1 \mathrm{RM}_{\mathrm{BP}}$

$\uparrow 3.7-8.1 \% 10-\mathrm{m}$

sprint

$\uparrow 7.8 \% \mathrm{COD}$

5-8 sets $x$ 6-10 VDJ or

HDJ $(25 \mathrm{~cm})$

$\uparrow 3.7-4.1 \% 25-\mathrm{m}$

sprint with COD

$\uparrow 3-8.6 \% \mathrm{CMJ}$

$\uparrow 2 \%$ Throw speed

release $\uparrow 12.2 \% 1 \mathrm{RM}_{\mathrm{LP}}$

$\uparrow 22.9 \% 1 \mathrm{RM}_{\mathrm{PD}}$

Squat, Leg press,

Knee flexion curl,

Bench press, Pec-Dec.

1 set $x$ 12-10-6-3 at 40-50-80-90\% 1RM

2-3 sets x 4-6 Squat,

Bench Press and

Pullover

(80-95\% 1RM)

10 weeks

(2 sessions/week) $\uparrow 13.3 \%$ Isometric unilateral leg extension force

$\uparrow 9 \%$ Isometric unilateral leg flexion force

$\uparrow 3.2 \%$ throw speed

$\uparrow 42.4 \%$ run-up throw speed

$\uparrow 33.3 \%$ throw speed $\uparrow 14.7 \% 1 \mathrm{RM}_{\mathrm{BP}}$ $\uparrow 50.1 \% 1 \mathrm{RM}$ PU
2-4 sets x 3-6 Squat,

Bench Press and

Pullover

(55-55\% 1RM) $\uparrow 37.6 \%$ run-up throw speed $\uparrow 23.8 \% 1 \mathrm{RM}_{\mathrm{BP}}$ $\uparrow 6.5 \% 1 \mathrm{RM} \mathrm{PU}_{\mathrm{P}}$ 


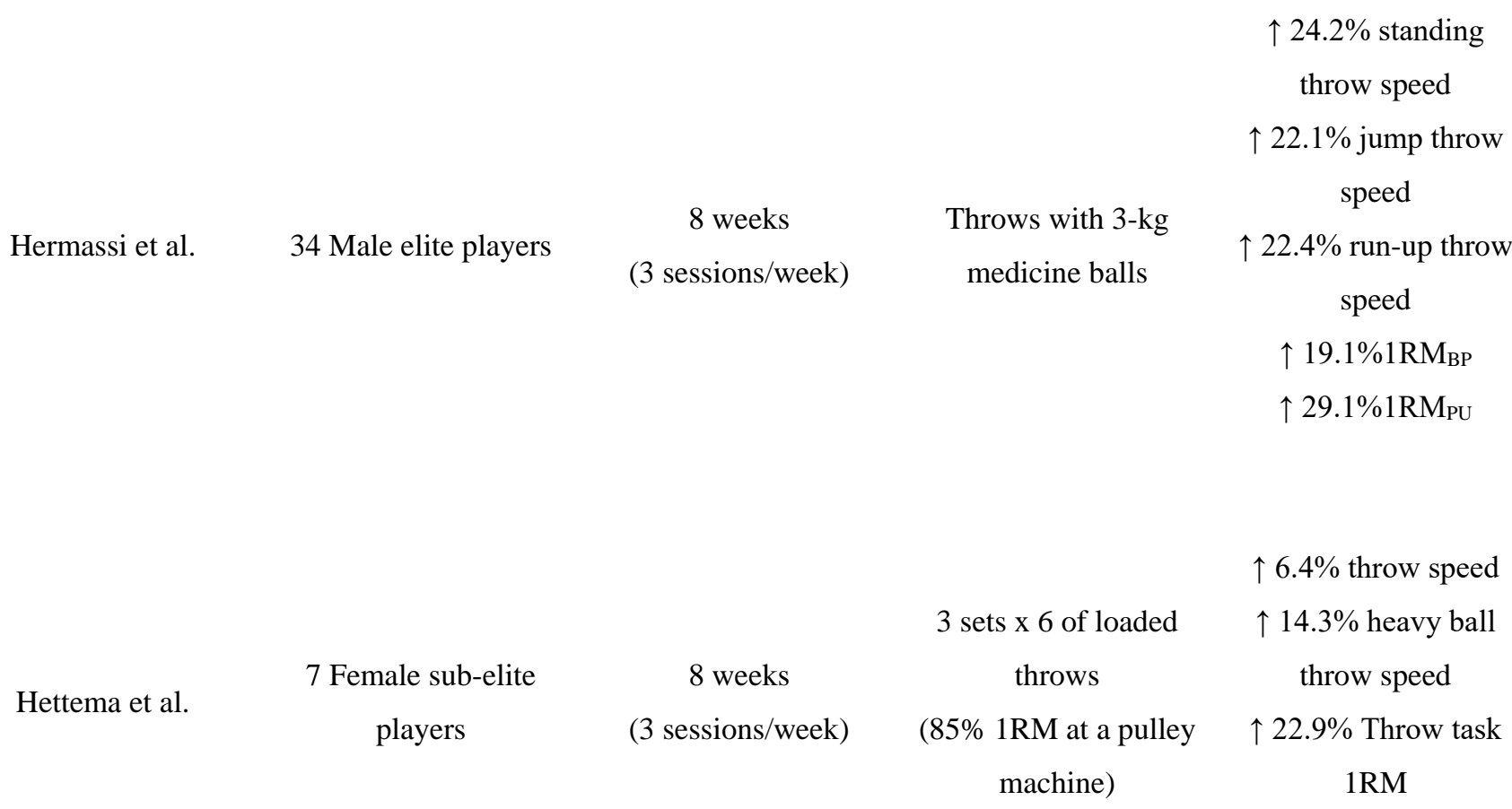

$\begin{array}{ccccc}\text { Hernández-Davó et al. 28 Male junior players } & \begin{array}{c}4 \text { weeks } \\ (2 \text { sessions/week })\end{array} & \begin{array}{c}\text { Rebound BP throw } \\ (30-50-70 \% 1 \mathrm{RM})\end{array} & \begin{array}{c}\uparrow 10-12 \% \text { Throw } \\ \text { speed release }\end{array} \\ \text { Hoff \& Almasbakk } & \begin{array}{c}\text { 6 Female second } \\ \text { national level }\end{array} & \begin{array}{c}9 \text { weeks } \\ \text { (3 sessions/week })\end{array} & \begin{array}{c}3 \text { sets x 5-6 Bench } \\ \text { press exercise }\end{array} & \begin{array}{c}\uparrow 17-18 \% \text { Throw } \\ \text { speed release }\end{array}\end{array}$

$(85 \%$ 1RM)

$\begin{array}{ccc}\text { Raeder et al. } & \text { 28 Female amateur } & 6 \text { weeks } \\ \text { players } & \text { (3 sessions/week) }\end{array}$
$1-3$ sets $x$ 6-12 throws with 1 - and 2-kg medicine balls

$\uparrow 14.3 \%$ Standing throw speed $\uparrow 15.4 \%$ Shoulder Moment $\mathrm{IR}_{180}$

$\uparrow 9.1-9.6 \% 1 \mathrm{RM}_{\mathrm{BP}}$

4 weeks

Sabido et al. 28 Male junior players (2 sessions/week) Rebound BP throw (30-50-70\% 1RM)

$\uparrow 3.4-4.7 \%$ Standing throw speed $\uparrow 3.4-5.3 \%$ Jumping throw speed 


$\begin{array}{ccccc}\text { Saeterbakken et al. } & \text { 34 Female high- } & 6 \text { weeks } & \text { Core Stability } & \uparrow 4.9 \% \text { Throwing } \\ & \text { school players } & (2 \text { sessions/week }) & \text { program } & \text { speed }\end{array}$

Note: RM: maximal repetition; CMJ: countermovement jump; JR: jump and reach; 1RM $\mathrm{BP}_{1} 1$ maximal repetition in bench press exercise; COD: change of direction; BP: bench press; 1RMPU: 1 maximal repetition in pullover exercise; $\mathrm{IR}_{180}$ : Isokinetic internal rotation moment at 180 degrees/second; $1 \mathrm{RM}_{\mathrm{LP}}$ : 1 maximal repetition in leg press exercise; $1 \mathrm{RM}$ PD: 1 maximal repetition in $\mathrm{Pec}$ dec exercise.

In conclusion, strength training is of fundamental importance for the athletic development of team handball players. Importantly, the paucity of data in the literature on the strength training applications among elite team handball players, requires an accurate understanding when selecting the most effective training prescriptions for elite handball players involved in national and international competitions during very long seasons. Regardless the limited information available, it appears that strength training can produce beneficial effects when strength programmes are planned consistently and progressively during the entire season. It should be reminded that a specific selection of the appropriate exercise and loading methodologies is needed due to the specific demands of the sport and the different requirements due to the playing positions. In fact, despite general improvements in personal strength levels, as expressed by 1RMs levels, should be aimed, the same adaptations would be worth of interest if they have a direct influence on handball-specific activities such as acceleration, jumping, sprinting, change of direction (COD) ability, throwing and effective defensive actions.

\section{References}

Aagaard P. Training-Induced Changes in Neural Function. Exerc Sport Sci Rev 31(2): 61-67, 2003.

Aagaard P, Simonsen EB, Andersen JL, Magnusson SP, Dyhre-poulsen P. Increased rate of force development and neural drive of human skeletal muscle following resistance training. $J$ Appl Physiol 93: 1318-1326, 2002.

Ahmaidi S, Granier P, Taoutaou Z, Mercier J, Dubouchaud H, Prefaut C. Effects of active recovery on plasma lactate and anaerobic power following repeated intensive exercise. Med Sci Sports Exerc 28:450-456, 1996.

Balsom PD, Seger JY, Sjödin B, Ekblom B. Maximal-intensity intermittent exercise: effect of recovery duration. Int J Sports Med 13: 528-533, 1992. 
Bangsbo J, Michalsik LB. The optimal training method. A scientific and practical approach to aerobic and anaerobic training. National Olympic Committee and Sports Confederation of Denmark, Copenhagen, Denmark, editors. [Den optimale træningsmetode. En videnskabelig og praktisk tilgang til aerob og anaerob træning. Danmarks Idræts-Forbund, København, Danmark, editors.], pp.1-345, 2018.

Barata J. Changes in ball velocity in the handball free throw, induced by two different speedstrength training programs. Portug. J. Hum. Perf. 8: 45-55. 1992.

Bogdanis GC, Nevill ME, Boobis LH. Lakomy HK, Nevill AM. Recovery of power output and muscle metabolites following $30 \mathrm{~s}$ of maximal sprint cycling in man. $J$ Physiol 15: 467-480, 1995.

Buchheit M, Millet GP, Parisy A, Pourchez S, Laursen PB, Ahmaidi, S. Supramaximal training and post-exercise parasympathetic reactivation in adolescents. Med Sci Sports Exer 40: 362-371, 2008 .

Buchheit M. The 30-15 Intermittent fitness test: accuracy for individualizing interval training of young intermittent sport players. J Strength Cond Res 22: 365-374, 2008.

Buchheit M, Laursen PB. High-intensity interval training, solutions to the programming puzzle. Part II: anaerobic energy, neuromuscular load and practical applications. Sports Med 43: 927-954, 2013.

Buchheit M, Laursen PB, Kuhnle J, Ruch D, Renaud C, Ahmaidi S. Game-based training in young elite handball players. Int J Sports Med 30: 251-258, 2009.

Contreras B, Vigotsky AD, Schoenfeld BJ, Beardsley C, McMaster DT, Reyneke JH, Cronin J. B. Effects of a six-week hip thrust vs. front squat resistance training program on performance in adolescent males: a randomized controlled trial. J Strength Cond Res 4: 999-1008, 2017.

Cormie P, McGuigan MR, Newton RU. Developing maximal neuromuscular power: Part 1biological basis of maximal power production. Sports Med 1: 17-38, 2001.

Dello Iacono A, Eliakim A, Meckel Y. Improving fitness of elite handball players: small-sided games vs. high-intensity intermittent training. J Strength Cond Res 29: 835-843, 2015.

Dello Iacono A, Martone D, Milic M, Padulo J. Vertical- vs. horizontal-oriented drop jump training: chronic effects on explosive performances of elite handball players. J Strength Cond Res, 4: 921-931, 2017.

Dello Iacono A, Martone D, Padulo J. Acute effects of drop-jump protocols on explosive performances of elite handball players. J Strength Cond Res 11: 3122-3133, 2016.

Dello Iacono A, Padulo J, Seitz LB. Loaded hip-thrust-based PAP protocol effects on acceleration and sprint performance of handball players. Journal of Sports Sciences 5: 1-8, 2017.

Ettema G, Glosen T, van den Tillaar R. Effect of specific resistance training on overarm throwing performance. Int J Sports Physiol Perform 2:164-175, 2008.

Gerbino A, Ward SA, Whipp BJ. Effects of prior exercise on pulmonary gas-exchange kinetics during high-intensity exercise in humans. J Appl Physiol 80: 99-107, 1996.Gløsen, T. Trening 
studiet for $\mathrm{a}^{\circ}$ se effekten av spesifikk styrke og variable teknikk trening $\mathrm{pa}^{\circ}$ skuddhastigheten I handballskuddet. Master's thesis, Norwegian University of Science and Technology, Trondheim, 2001 .

Hermassi S, Castagna C, Mohamed HY Younes H, Chamari K. Direct validity of the yo-yo intermittent recovery test in young team handball players. J Strength Cond Res 24: 465-470, 2010.

Hermassi S, Chelly MS, Fathloun M, Shephard RJ. The effect of heavy- vs. moderate-load training on the development of strength, power, and throwing ball velocity in male handball players. J Strength Cond Res 9: 2408-2418, 2010.

Hermassi S, van den Tillaar R, Khlifa R, Chelly MS, Chamari K. Comparison of in-seasonspecific resistance vs. a regular throwing training program on throwing velocity, anthropometry, and power performance in elite handball players. J Strength Cond Res 8: 2105-2014, 2015.

Hoff J, Almåsbakk B. The effects of maximum strength training on throwing velocity and muscle strength in female team-handball players. J Strength Cond Res 4:255-258, 1995.

Issurin VB. Training transfer: scientific background and insights for practical application. Sports Med 8: 675-694, 2013.

Laursen PB, Jenkins DG. The scientific basis of high-intensity interval training: optimising training programmes and maximising performance in highly trained endurance athletes. Sports Med 32: 53-73, 2002.

Luig P, Lopez CM, Pers J, Perse M, Kristan M, Schander I, Zimmermann M, Henke T, Platen P. Motion characteristics according to playing position in international men's Team Handball. In: Cabri J, Alves F, Araujo D, Barreiros J, Diniz J, Veloso A (eds.). Sport Science by the sea. Proceedings of the 13th Annual Congress of the European College of Sport Science, Estoril, Portugal, 9-12 July 2008, pp. 241-242, 2008.

Marques MC, González-Badillo JJ. In-season resistance training and detraining in professional team handball players. J Strength Cond Res 3: 563-71, 2006.

Markovic G, Mikulic P. Neuro-musculoskeletal and performance adaptations to lower-extremity plyometric training. Sports Med 10: 859-895, 2010.

Michalsik LB. Preparation and Training of Elite Team Handball Players. In: European Handball Federation (eds.). Medical Aspects in Handball - Preparation and the Game: Scientific and Practical Approaches. Proceedings of the third International Conference on Science in Handball, Bucharest, Romania, 13-14 Nov 2015. pp. 60-67, 2015.

Michalsik LB, Aagaard P. Physical demands in elite team handball: Comparisons between male and female players. J Sports Med Phys Fitness 55(9): 878-891, 2015.

Michalsik LB, Aagaard P, Madsen K. Locomotion Characteristics and Match Induced Impairments in Physical Performance in Male Elite Team Handball Players. Int J Sports Med 34(7): 590-599, 2013.

Michalsik LB, Madsen K, Aagaard P. Match Performance and Physiological Capacity of Female Elite Team Handball Players. Int J Sports Med 35(7): 595-607, 2014. 
Michalsik LB, Madsen K, Aagaard P. Technical match characteristics and influence of body anthropometry on playing performance in male elite team handball. J Strength Cond Res 29(2): 416-428, 2015a.

Michalsik LB, Aagaard P, Madsen K. Technical activity profile and influence of body anthropometry on playing performance in female elite team handball. J Strength Cond Res 29(4): 1126-1138, 2015b.

Michalsik LB, Madsen K, Aagaard P. Physiological capacity and physical testing in male elite team handball. J Sports Med Phys Fitness 55(5): 415-429, $2015 \mathrm{c}$.

Morin JB, Samozino P. Interpreting Power-Force-Velocity profiles for individualized and specific training. Int J Sports Physiol Perform 2: 267-272, 2016.

Raeder C, Fernandez-Fernandez J, Ferrauti A. Effects of six weeks of medicine ball training on throwing velocity, throwing precision, and isokinetic strength of shoulder rotators in female handball players. J Strength Cond Res 7: 1904-1914, 2015.

Sabido R, Hernández-Davó JL, Botella J, Moya M. Effects of 4-week training intervention with unknown loads on power output performance and throwing velocity in junior team handball players. PLoS One 6: e0157648, 2016.

Saeterbakken AH, van den Tillaar R, Seiler S. Effect of core stability training on throwing velocity in female handball players. J Strength Cond Res 3: 712-718.

Sale DG. Postactivation potentiation: role in human performance. Exercise and Sport Sciences Reviews 30: 138-143, 2002.

Seitz LB, Haff GG. Factors modulating Post-activation potentiation of jump, sprint, throw, and upper-body ballistic performances: a systematic review with meta-analysis. Sports Med 2: 231$240,2016$.

Sibila M, Vuleta D, Pori P. Position-related differences in volume and intensity of lange-scale cyclic movements of male players in handball. Kinesiology 36(1): 58-68, 2004.

Pori P, Šibila, M. Analysis of high-intensity large-scale movements in team handball. Kinesiologia Slovenica 12(2): 51-58, 2006.

Wagner H, Fuchs PX, von Duvillard SP. Specific physiological and biomechanical performance in elite, sub-elite and in non-elite male team handball players. J Sports Med Phys Fitness 2017. [Epub ahead of print] 